\title{
TEACHER OPINIONS ON SEXUAL EDUCATION OF STUDENTS WITH INTELLECTUAL DISABILITY IN LATVIA
}

\author{
Egija Laganovska \\ University of Latvia, Latvia \\ Elīna Kviese \\ University of Latvia, Latvia
}

\begin{abstract}
Sexual education plays an important role in preparing children and adolescents for a safe and productive life. Sex education provides not only knowledge about different types of sexual issues, or about common sexually transmitted diseases, unwanted pregnancies, sexual violence, but also personal identity, safety, love, intimacy and relationships.

This study was conducted in order to examine the opinions of special education teachers working with adolescents with intellectual disabilities on sexual education. A descriptive study design was used. The authors designed a questionnaire to explore the opinions of 72 special education teachers in Latvia.

The research results approved how crucial it is to provide opportunities to receive sexual education for adolescents with intellectual disabilities at school.
\end{abstract}

Keywords: adolescent, intellectual disabilities, sexual education, special education teachers.

\section{Introduction}

Adolescents with intellectual disabilities have the same rights as those without disabilities, but many of these adolescents face challenges to the attainment of their right to healthy sexual development. For adolescents with intellectual disabilities, schools are often the main source of information for learning about sexuality; therefore, the provided education needs to be of good quality to support students in their transition from childhood into adulthood.

The aim of this study is to explore the opinions of special education teachers on sexual education provided at school for adolescents with intellectual disabilities and to promote a discussion about the particular issue. During this research 72 special education teachers have been surveyed.

Research methods: a scientific literature analysis, a survey of special education teachers from Latvia (72 respondents), a data collection and analysis.

The article is based on research results presented in the Diploma Paper by Elīna Kviese (2020). 
Laganovska \& Kviese, 2021. Teacher Opinions on Sexual Education of Students with Intellectual Disability in Latvia

\section{Literature Review}

General sexual education can be defined as a teaching and learning process where cognitive, emotional, physical and social aspects of sexuality are studied. The aim is to ensure that children and young people gain knowledge, skills and values that will enable them to be aware of their health, well-being and respect, to develop respectful social and sexual relationships, to understand how their choices can affect one's own and other people's well-being, to understand and ensure the protection of rights (UNESCO, 2018). Schaafsma, Stoffelen, Kok and Curfs (2012) state that sexual education can considerably improve social skills, behaviour, decision making skills and knowledge.

Children with intellectual disabilities, like any other adolescents, reach their puberty. Some children reach it quite early (at the age of 5), others experience delayed puberty (at the age of 20). This is the period when adolescents become strongly motivated to build sexual and romantic relationships with other people. Adolescents with intellectual disabilities experience various sexual sensations as their peers; there are adolescents who consider sexual activities as insignificant, meanwhile, some adolescents think about sexual activities constantly. These adolescents can face challenges to understand their sensations, thus an additional support is required to educate them about the experienced sensations, skills how to express them and act accordingly.

F. Brown and S. Brown (2016) declare that a neglected upbringing can lead to inappropriate behaviour. People with intellectual disabilities are vulnerable for various reasons, for instance, they constantly depend on others, are socially isolated, over-protected, and the lack of understanding of surrounding people about their sexual development can lead to a suppression of sexual and psychosocial development, a lack of sexual education, sexual violence and treating these individuals as less socially significant (Güven, İşler, 2014). Adolescents with intellectual disabilities are 50\% more likely to have unprotected sex in comparison with their peers without intellectual disabilities. Girls with intellectual disabilities get pregnant more often (Baines, Emerson, Robertson, Hatton, 2018). Besides, individuals with disabilities have a higher risk to sexual abuse (Hartman, 2014), sexually transmitted diseases and drug abuse (Lunsky, Durbin, Brown, Bansal, Heifetz and Antoniou, 2017). Consequently, the adolescent sexual education should be initiated before individuals have started their sexual life. In addition, the research carried out by Kammes, Douglas, Maas and Black (2020) indicates that parents express their wish that schools introduced sexual education even more.

Adolescents with intellectual disabilities often feel lonely, not being understood, they long for romantic relationships, however, are incapable to 
establish them. Wickström, Larsson and Höglund (2020) point out that even if these adolescents with intellectual disabilities could begin their relationships, there is a little chance that the romantic partners could spend certain time together as a couple in the environment they live.

It should be admitted that there is limited information available on sexuality, compared to the rest of population. There are several reasons for that, for example, limitations for learning, available resources, having a content that is written in the easy and plain language with relevant images. Couwenhoven (2001) highlights another serious reason that adults avoid having conversations about topics on sexuality; moreover, they often characterise it as something wrong. Also, Tamas, Brkic-Jovanovic, Rajic and Prkosovacki (2019) state that, indeed, sexuality is an embarrassing and contradictory topic for adolescents with intellectual disabilities, for their family members and other people they live together, and for professionals.

It is assumed that parents should be the primary source of information about sexuality for their children, sharing also values of the family (Hartman, 2014). Parents and professionals should work together to support adolescents with intellectual disabilities, although this is a complex task, because parents and professionals do not always have the same point of view (Couwenhoven, 2001). Tamas et al. (2019) indicate that when there are contradictory views and different values of parents and professionals, their collaboration is less qualitative and can cause confusion and raise false hopes regarding adolescents with intellectual disabilities.

Teachers often have a laid-back attitude of "if they do not ask, there is no need to explain” (F. Brown \& S. Brown, 2016). Social care employees, working with adolescents with intellectual disabilities, admit that they have heard comments stated by society and colleagues that definitely there is no need to talk about sexuality related topics, for example, stating that "do not wake the sleeping bear" or "we do not ask and do not even raise the question, do not give them the chance even to talk, you do not even mention sexuality" (Wickström et al., 2020, 5). A negative attitude exists towards a homosexual intercourse; Abbott and Howarth (2006) see plausible reasons for that and argue that it is due to the lack of knowledge and confidence how to educate adolescents with intellectual disabilities on such topics, and intentions to avoid disagreements between parents and professionals. Although there are professionals who admit their incompetence and ignore problems, the majority of professionals have a positive attitude, in general (Tamas et al., 2019; Wickström et al., 2020).

Adolescents seek for information from different sources: friends, television, Internet. Asagba, Burns and Doswell (2019) remind that these sources are both useful and harmful, even dangerous. Besides, the study of Löfgren-Mårtenson (2012) shows that adolescents with intellectual disabilities 
Laganovska \& Kviese, 2021. Teacher Opinions on Sexual Education of Students with Intellectual Disability in Latvia

acknowledge their willingness to gain additional information about sexual education. According to Frawley and Wilson (2016), adolescents with intellectual disabilities consider that teachers have not shared enough information about these topics that are essential to them at this age; therefore, teachers should address these issues more seriously and evaluate what kind of information should be provided for their students.

\section{Results and Discussion}

This study was conducted in order to examine the opinions of special education teachers, working with adolescents with intellectual disabilities, on sexual education that is provided at school. A descriptive study design was used. The authors designed a questionnaire as a data collection instrument to explore the opinions of 72 special education teachers in Latvia.

The gained results indicate that sexual education is important for students with intellectual disabilities to be provided at school, with reference to the views of special education teachers (see Figure 1). Figure 1 shows that there were $48 \%$ of teachers who strongly agreed and $44 \%$ agreed to this statement.

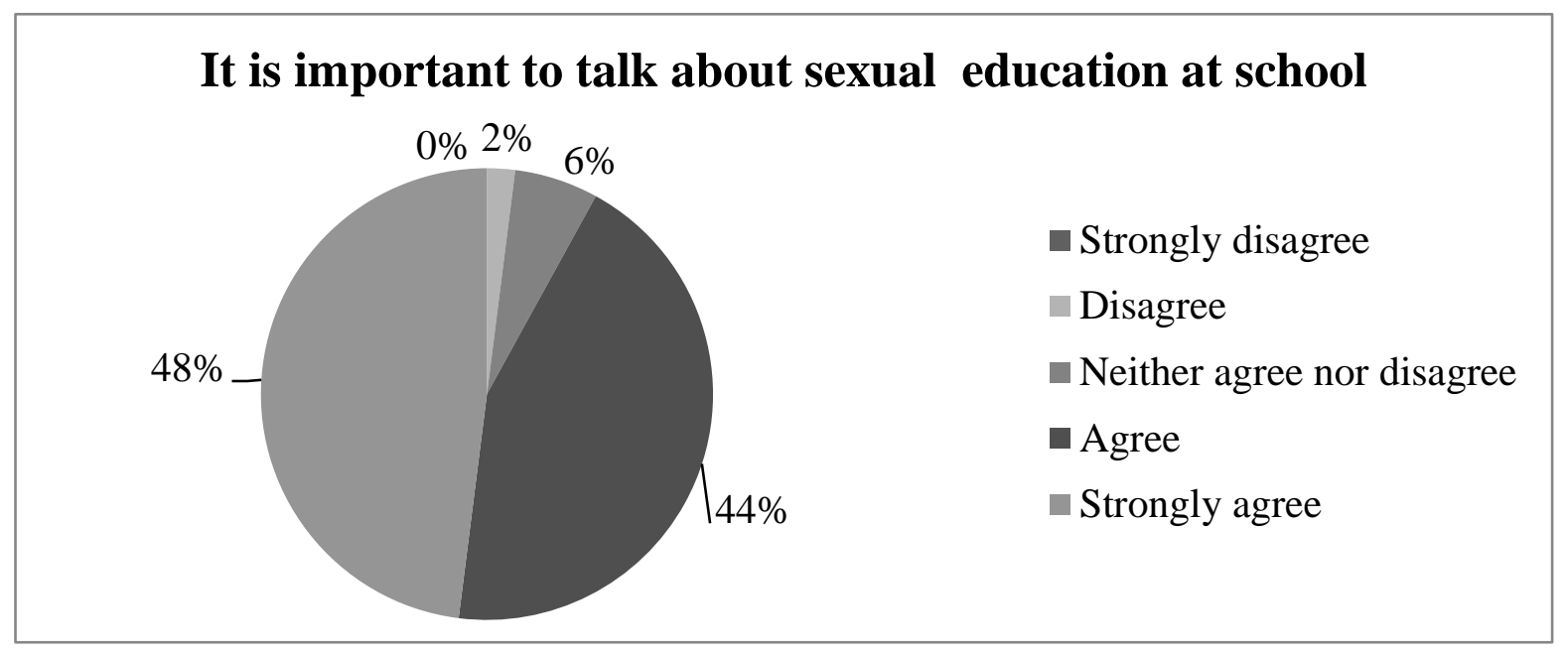

Figure 1 Teachers' Opinion on the Need for Sexual Education at School

There were $8 \%$ of respondents who stated that sexual education should not be a part of school curricula. The theoretical findings allow the authors of this study to explain such opinions of special education teachers; they see it as a parental responsibility. Thus, the teachers were inquired about the involvement of parents for providing sexual education for their adolescent children. Figure 2 illustrates the gained responses. 53\% of teachers replied that parents showed no interest regarding their children's sexual education. Besides, it is worth deeper discussions why there were $25 \%$ of special education teachers who were not 
informed about the parental involvement for these issues. It could be considered that a part of teachers does not devote close attention to adolescent sexual education related questions when collaborating with students' parents. However, it was highlighted that parents were contacted and informed in majority of cases when a deviant sexual behaviour was observed. The respondents admitted that parents not only frequently felt uncomfortable talking about sexuality, but they also had limited information about sexual issues. This indicates that sexual education involves highly sensitive topics; furthermore, it demands that parents should have a profound understanding of their own experiences, relationships, beliefs and values.

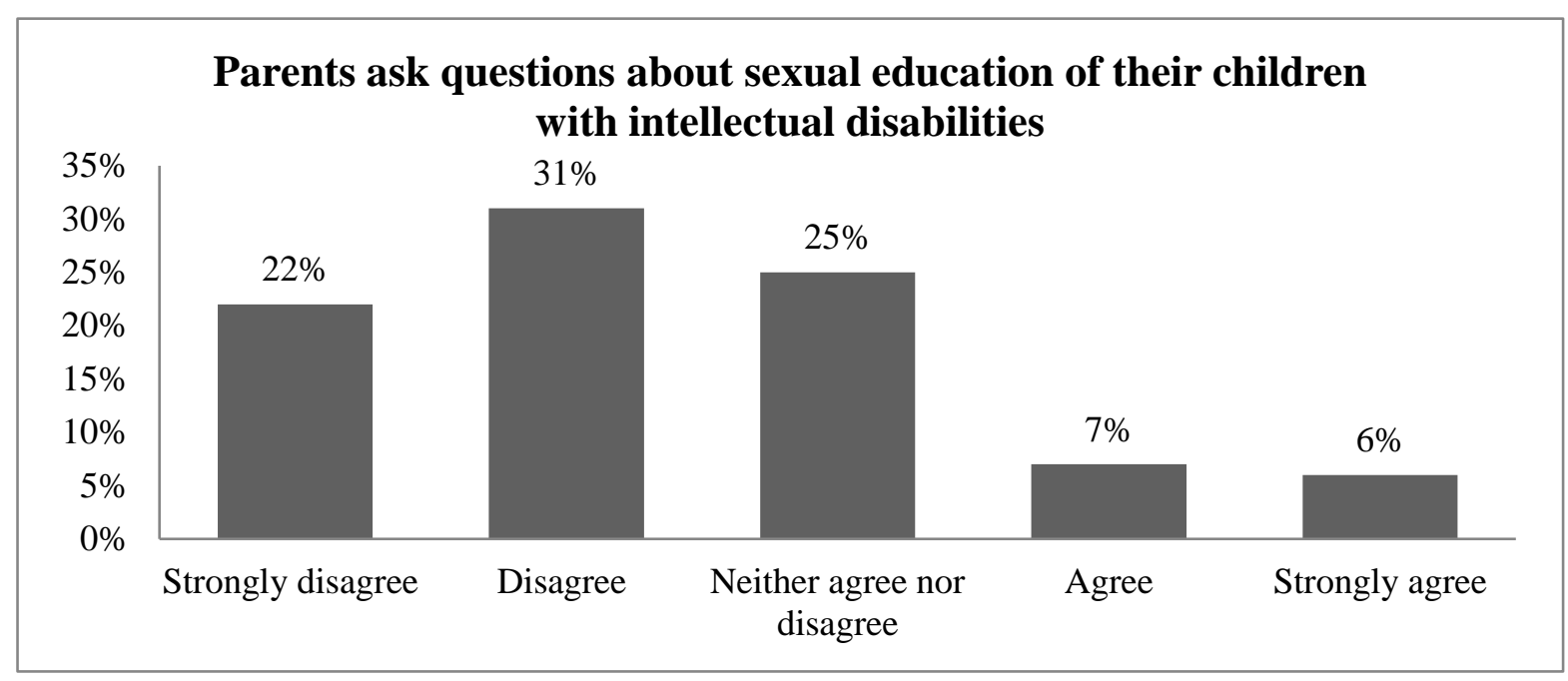

Figure 2 Parental Involvement in Sexual Education at School

Figure 3 demonstrates the opinions of special education teachers on their own feelings when talking about various sexual issues with their students. A part of teachers, like the students' parents, stated that they did not feel comfortable when addressing such issues. Although $72 \%$ of teachers noted that they felt comfortable when talking to students with intellectual disabilities about sexual issues, $18 \%$ of teachers highlighted it as a problematic concern.

It was discovered that there were certain topics that special education teachers did not focus on due to their consideration that thus they could provoke additional interest of these adolescents. More than half of respondents (66\%) replied that they strongly agreed or agreed that there was no need to discuss sexual relationships related topics in depth (see Figure 4). However, 24\% of teachers supported the need for deeper insights into such topics. The scientific literature studies and the gained research results let the authors of this article to conclude that the majority of special education teachers believe that an open discussion on sexuality related topics can increase students' interest in sexual relationships, which the teachers would want to avoid. 
Laganovska \& Kviese, 2021. Teacher Opinions on Sexual Education of Students with Intellectual Disability in Latvia

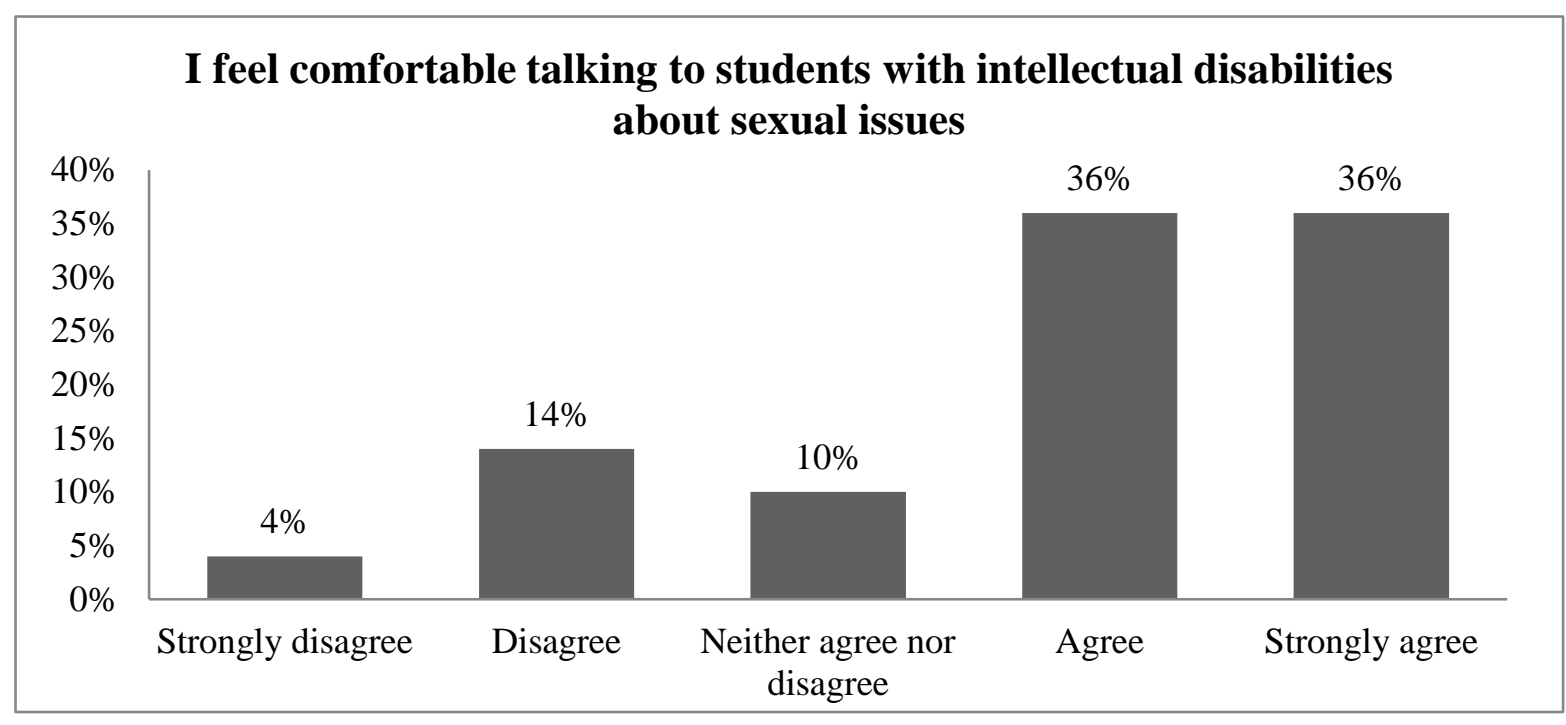

Figure 3 Teachers' Opinion on Their Feelings when Talking to Students with Intellectual Disabilities about Sexual Issues

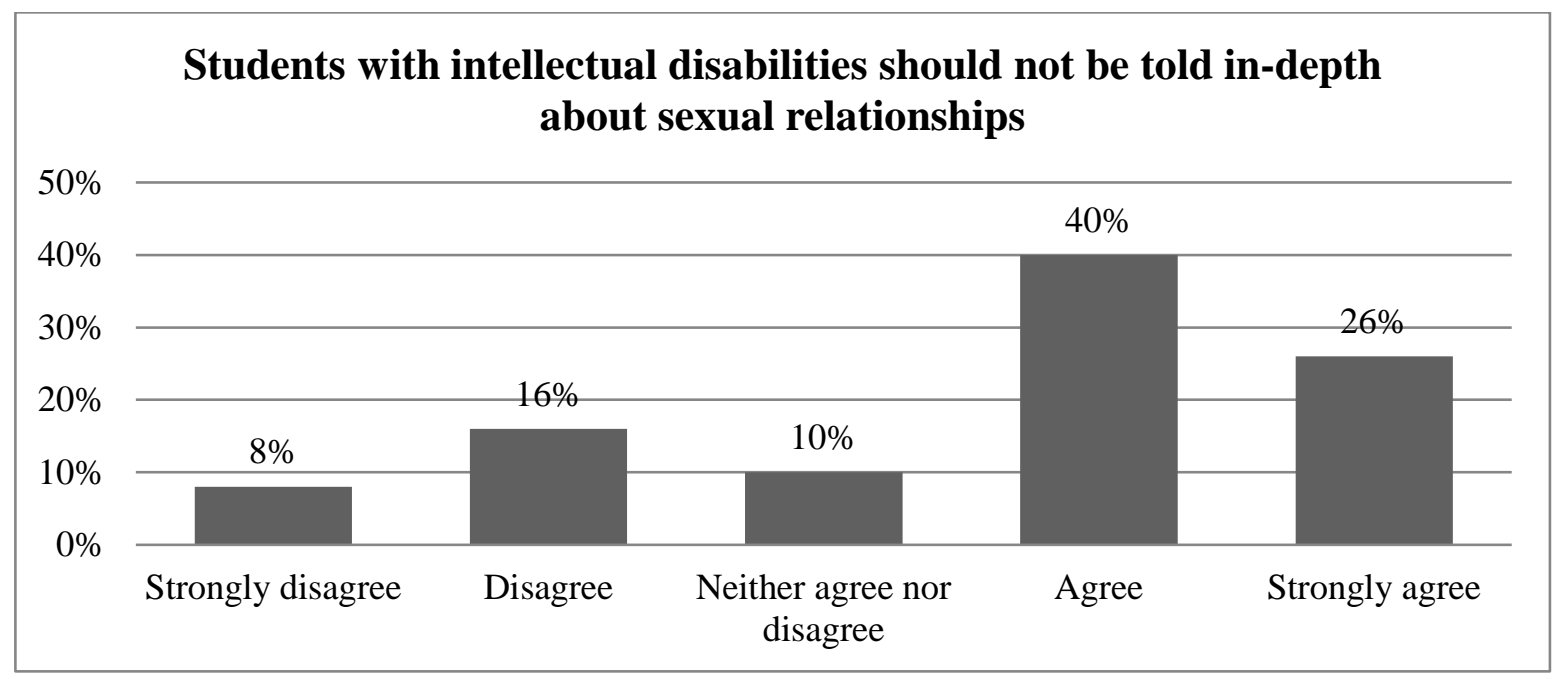

Figure 4 The Necessity of In-depth Knowledge about Sexual Relationships among Students with Intellectual Disabilities

Due to the lack of well-developed guidelines related to the current curriculum, teaching and learning materials and adequate supplementary resources on sexual issues for students with intellectual disabilities, the teachers are considerate about their pedagogical methods. Since the teachers' success or failure to enable the comprehension of adolescents on the contents of sexual education would either shape or shake the adult years of these students. It is evidenced in Figure 5 that the respondents expressed readiness to deepen their professional knowledge about teaching sexual education for students with intellectual disabilities (34\% strongly agreed, 36\% agreed). On the other hand, 
there were $16 \%$ of special education teachers who stated that they did not see any need for additional professional education.

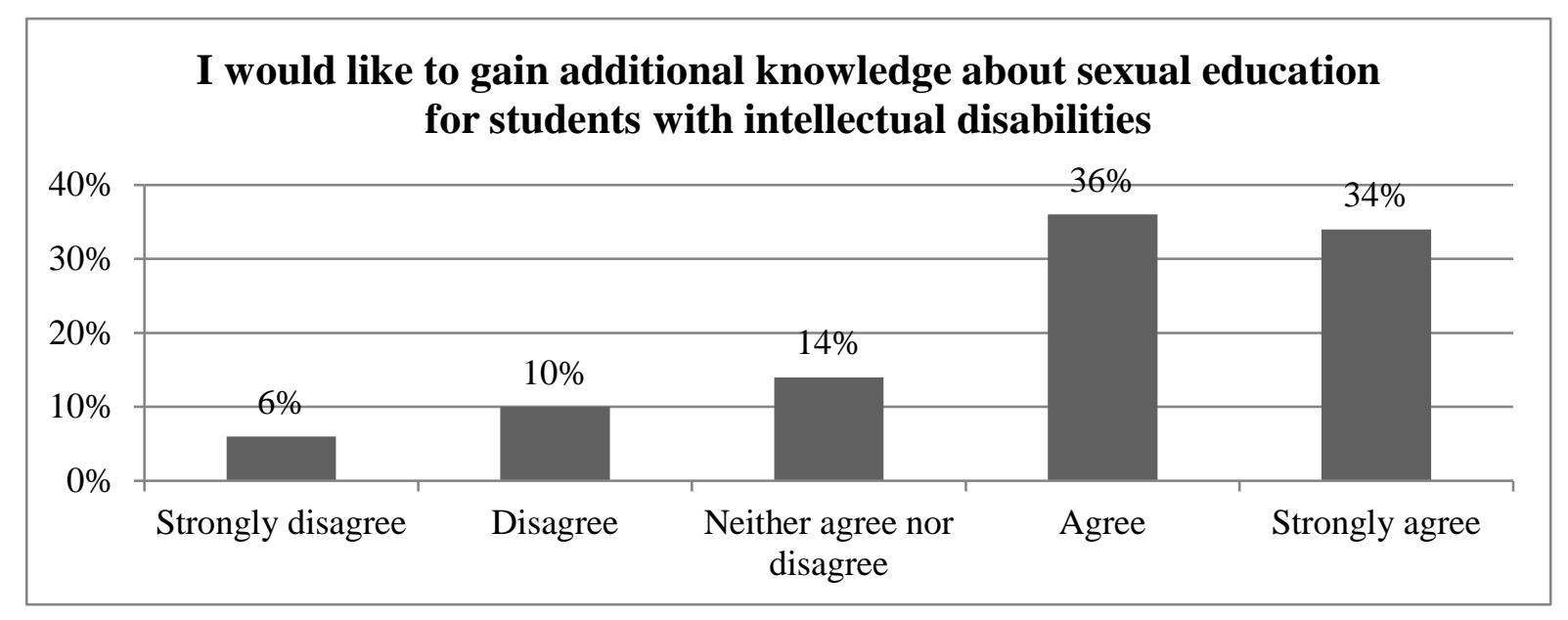

Figure 5 Teachers' Opinion on the Necessity for Additional Knowledge about Sexual Education for Students with Intellectual Disabilities

Teachers need a variety of skills, education and training to teach with confidence about sexual issues for their students. The results demonstrate that schools, however, lack common guidelines for the cases when students with intellectual disabilities show inappropriate sexual behaviour (see Figure 6). A small majority of respondents claimed that their schools had clear guidelines for a procedure to accomplish when facing inappropriate sexual behaviour of students (26\% strongly agreed, 38\% agreed). Special education teachers of sexual education need continuous professional training and support from their school administration.

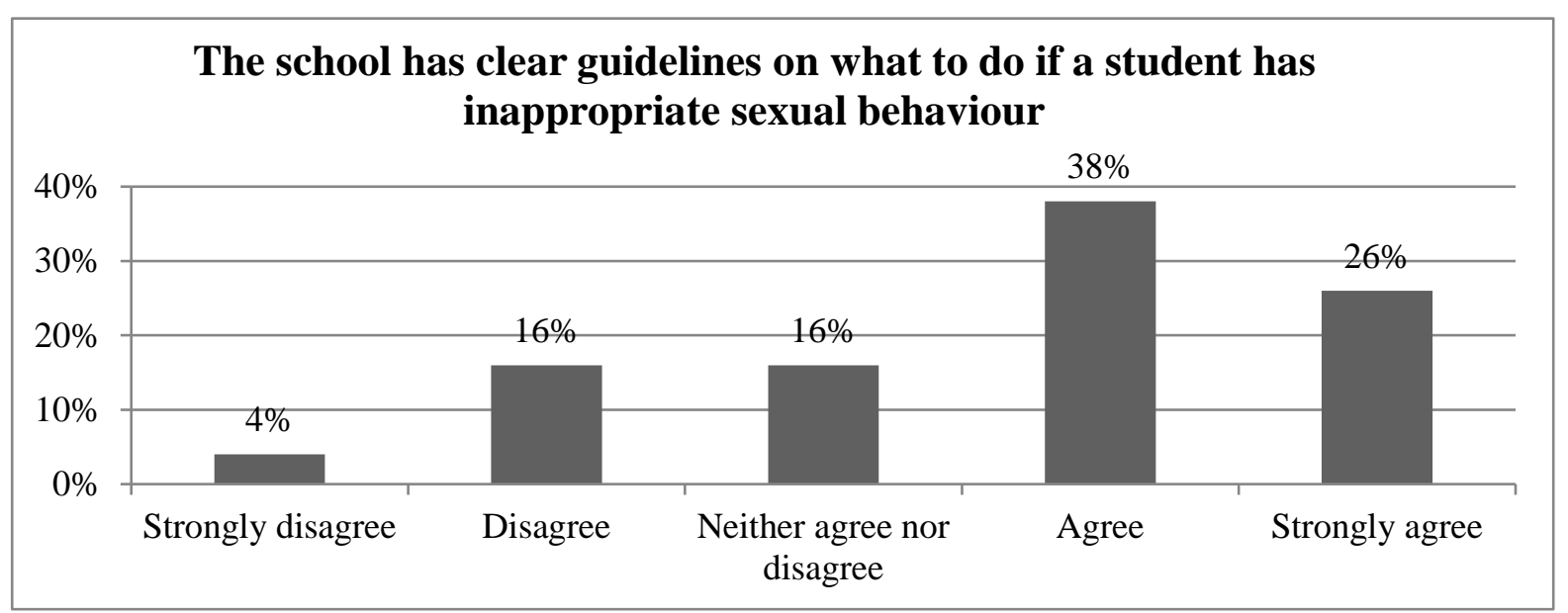

Figure 6 Teachers' Opinion on the Existence of Guidelines for a Procedure to Face Inappropriate Sexual Behaviour of Students 
Laganovska \& Kviese, 2021. Teacher Opinions on Sexual Education of Students with Intellectual Disability in Latvia

Apart from the previously presented data, an interesting fact is that the majority of special education teachers are aware where to seek for assistance in case of inquiry on questions related to sexual education (see Table 1).

Table 1 Teachers' Opinion on Their Knowledge and Confidence about Sexual Education

\begin{tabular}{|l|l|l|l|l|l|}
\hline & $\begin{array}{l}\text { Strongly } \\
\text { disagree }\end{array}$ & Disagree & $\begin{array}{l}\text { Neither } \\
\text { agree nor } \\
\text { disagree }\end{array}$ & Agree & $\begin{array}{l}\text { Strongly } \\
\text { agree }\end{array}$ \\
\hline $\begin{array}{l}\text { I have sufficient } \\
\text { knowledge of the } \\
\text { peculiarities of sexual } \\
\text { development for } \\
\text { adolescents with } \\
\text { intellectual disabilities. }\end{array}$ & $\mathbf{0 \%}$ & $\mathbf{2 \%}$ & $\mathbf{4 \%}$ & $\mathbf{6 8 \%}$ & $\mathbf{2 6 \%}$ \\
\hline $\begin{array}{l}\text { I feel competent teaching } \\
\text { students with intellectual } \\
\text { disabilities about } \\
\text { inappropriate sexual } \\
\text { behaviour. }\end{array}$ & $\mathbf{2 \%}$ & $\mathbf{1 4 \%}$ & $\mathbf{6 \%}$ & $\mathbf{5 6 \%}$ & $\mathbf{2 2 \%}$ \\
\hline $\begin{array}{l}\text { If I have any questions } \\
\text { about sexual education, I } \\
\text { know where to look for } \\
\text { information. }\end{array}$ & $\mathbf{4 \%}$ & $\mathbf{1 2 \%}$ & $\mathbf{8 \%}$ & $\mathbf{3 6 \%}$ & $\mathbf{4 0 \%}$ \\
\hline
\end{tabular}

$76 \%$ of respondents indicated that they knew where to look for information, $78 \%$ felt confident to teach students with intellectual disabilities about inappropriate sexual behaviour, meanwhile, $94 \%$ of respondents noted that they had sufficient knowledge about the peculiarities of sexual development for adolescents with intellectual disabilities.

\section{Conclusion}

The research shows that it is crucial to provide opportunities to receive sexual education for adolescents with intellectual disabilities at school. When these students are not informed about sexuality, they have difficulty identifying their experiences and perceive that their exploitative behaviours are wrong. There is a need for educational programmes that focus on sexuality development for students with intellectual disabilities, in particular. Moreover, the involvement of family in the child's sexual education should be considered, as it is done in any other fields of education. Parents play a primary role in disseminating sexual information; they develop their children's sexual identity and foster sexual and social relationships. This is a vital issue in educational institutions that invites for in-depth discussions among the specialists of the 
field. What are the challenges that special education teachers face throughout their experience of teaching sexual education? The key finding are as follows:

1. Sexual education is an area of concern for many special education teachers and parents.

2. The aim of sexual educational programmes in special education should be set to provide students with knowledge and skills to defend themselves against sexual violence, sexually transmitted diseases and unwanted pregnancies, what is more, to give information and increase students' knowledge about healthy and responsible sexual behaviours.

3. It is essential that students with intellectual disabilities have courses that help them to continue their sexual education and participate in discussions about sexual education and their sexuality.

\section{References}

Abbott, D., \& Howarth, J. (2006). Still Off-Limits? Staff Views on Supporting Gay, Lesbian and Bisexual People with Intellectual Disabilities to Develop Sexual and Intimate Relationships? Journal of Applied Research in Intellectual Disabilities, 20, 116-126. DOI: 10.1111/j.1468-3148.2006.00312.x

Asagba, K., Burns, J., \& Doswell, S. (2019). Sex and Relationships Education for Young People and Adults with Intellectual Disabilities and Autism. West Sussex: Pavilion Publishing and Media.

Baines, S., Emerson, E., Robertson, J., \& Hatton C. (2018). Sexual Activity and Sexual Health among Young Adults with and Without Mild/Moderate Intellectual Disability. Public Health, 18, 1-12. DOI: 10.1186/s12889-018-5572-9.

Brown, F. J., \& Brown, S. (2016). When Young People with Intellectual Disabilities and Autism Hit Puberty. London: Jessica Kingsley Publisher.

Couwenhoven, T. (2001). Sexuality Education: Building a Foundation for Healthy Attitudes. Disability Solutions, 4, 1-16.

Frawley, P., \& Wilson, N. (2016) Young People with Intellectual Disability Talking About Sexuality Education and Information. Sexuality and Disability. DOI: 10.1007/s11195016-9460-X

Güven, Ş. T., \& İşler, A. (2014). Sex Education and Its Importance in Children with Intellectual Disabilities. Journal of Psychiatric Nursing, 6, 143-148.

Hartman, D. (2014). Sexuality and Relationship Education for Children and Adolescents with Autism Spectrum Disorders. London: Jessica Kingsley Publishers.

Kammes, R. R., Douglas, S. N., Maas, M. K., \& Black, R. S. (2020). Parental Support for Sexuality Education and Expression among Adults with an Intellectual Disability. Sexuality and Disability, October.

Kviese, E. (2020). Seksuālā izglītošana pusaudžiem ar garīgās attīstības traucējumiem. Diplomdarbs. Rīga: Latvijas Universitāte.

Löfgren-Mårtenson, L. (2012) “I Want to Do it Right!” A Pilot Study of Swedish Sex Education and Young People with Intellectual Disabilities. Sexuality and Disability, 30, 209-225. DOI: 10.1007/s11195-011-9239-z

Lunsky, Y., Durbin, A., Brown, H. K., Bansal, S., Heifetz, M., \& Antoniou, T. (2017). Health Profiles and Associated Service Use among Adults with HIV and Intellectual and 
Laganovska \& Kviese, 2021. Teacher Opinions on Sexual Education of Students with Intellectual Disability in Latvia

Developmental Disabilities. AIDS, 31, 697-705. DOI: 10.1097/QAD.0000000000 001361

Schaafsma, D., Stoffelen, J. M. T., Kok, G, \& Curfs, L. M. G. (2012). Exploring the Development of Existing Sex Education Programmes for People with Intellectual Disabilities: An Intervention Mapping Approach. Journal of Intellectual Disability Research, 26, 157-166. DOI: 10.1111/jar.12017

Tamas, D., Brkic-Jovanovic, N., Rajic, M., \& Prkosovacki, B. P. (2019). Professionals, Parents and the General Public: Attitudes Towards the Sexuality of Persons with Intellectual Disability. Sexuality and Disability. DOI: 10.1007/s11195-018-09555-2

UNESCO. (2018). International Technical Guidance on Sexuality Education. Retrieved from: https://unesdoc.unesco.org/ark:/48223/pf0000260770

Wickström, M., Larsson, M., \& Höglund, B. (2020). How Can Sexual and Reproductive Health and Rights Be Enhanced for Young People with Intellectual Disability? - Focus Group Interviews with Staff in Sweden. Reproductive Health, 17, 1-11. 